\title{
Effect of Different Concentrations of Sodium Cloride, Sodium Selenate, Alpha- Tocopherol and Ascorbic Acid Each One Alone on Germination and Growth of Maize Plant
}

\author{
A.G.Khalil ${ }^{1}$, F.M.Bassuony ${ }^{1}$, S.A.Haroun ${ }^{2}$, R.R.Khalil ${ }^{1}$ \\ ${ }^{1}$ Botany Dept., Faculty of Science, Benha Univ., Benha, Egypt \\ ${ }^{2}$ Botany Dept., Faculty of Science, Mansoura Univ., Mansoura, Egypt \\ E-Mail: amina.khalil@fsc.bu.edu.eg
}

\begin{abstract}
The present study was carried out to show the negative impact of different concentrations of sodium chloride (100, 150, 200,250 and $300 \mathrm{mM}$ ) on germination rate of 7-day old maize seeds, according to the results by measuring growth criteria of germinated maize seeds both 250 and $300 \mathrm{mM}$ of Nacl these conc $\mathrm{s}_{\mathrm{s}}$ nearly lethal to maize seed so, both of concentrations ignored in next experiments and complete next step with three conc $_{\mathrm{s}}$ only (100, 150 and $\left.200 \mathrm{mM}\right) \mathrm{Nacl}$. Also, our study was accomplished to improve growth rate of 15-day old maize plant under different concentrations of sodium selenate $(0.25$, $0.5,5,10,15,20$, and $25 \mu \mathrm{M})$, alpha-tocopherol (100, 150, 200, 250 and $300 \mathrm{ppm})$ and ascorbic acid (100, 150, 200, 250 and $300 \mathrm{ppm}$ ) each one alone, whereas growth parameter (shoot length, root length, fresh and dry weight of shoot and root, No. of leaves and leaf area per plant were estimated. The application of sodium selenate, alpha-tocopherol, and ascorbic acid each one alone by seed soaking resulted generally improve growth parameters of 15-day old maize plants as compared with untreated plants especially, $0.5 \mu \mathrm{M}$ of sodium selenate, $200 \mathrm{ppm}$ of alpha-tocopherol and $250 \mathrm{ppm}$ of ascorbic acid.
\end{abstract}

Keywords: Alpha-tocopherol, Ascorbic acid, Salinity, Selenium, Zea mays.

\section{Introduction}

Plants grown naturally are faced with all kinds of environmental factors, bringing about adverse changes to the patterns of growth and development. Salinity is one of the major environmental factors which can impede natural growth, development and metabolism [1]. Globally, salinity is a significant abiotic stress, affecting one-quarter to one-third of the crop productivity of agricultural soils [2]. It was estimated in 2003 that up to the middle of the 21 st century, the salinity-induced loss of cultivated soil will reach up to $50 \%$ [3]. In 2008, it was reported that, due to high salinization, 77 million hectares of the world's total cultivated area (1.5 billion hectares) was adversely affected [4]. At present, about $10 \%$ of the global land area and $50 \%$ of irrigated areas are exposed to salinity, causing a loss of about 12 billion US\$ in the agricultural sector [5].

In the near future, there is a tendency for the agricultural expansion of many crops, including Zea mays in newly reclaimed soils in Egypt. However, most of these soils are affected by salinity. Maize (Zea mays L.) is in the third rank after wheat and rice and is grown all over the world in a wide range of climatic condition. Being highly cross pollinated, maize has become highly polymorphic through the course of natural and domesticated evolution and thus contains enormous variability in which salinity tolerance may exist [1]. Maize, which belongs to the plants with $\mathrm{C} 4$ metabolism, is also classified as moderately sensitive to salinity [2, 3].

Efforts have been made to control salinity by various means, including foliar application of plants with some antioxidants, for developing the sustainable agriculture. Selenium acts as an essential trace element for animals and humans or act as toxicant to the environment, the boundary between the two is narrow and depends on its chemical form, concentration, and other environmentally regulating variables [4]. Plant Se levels are determined by Se uptake as well as translocation of Se from roots to the edible part of crops. Furthermore, plant Se uptake is largely determined by total soil Se concentrations, Se speciation, competing ions present in soils and other soil physicochemical factors $[5,6]$. In soils, Se can be present in both inorganic and organic forms as well as in different oxidation states (i.e. -II, -I, 0, IV, VI) [7]. Plants take up Se primarily in two forms, either as selenate $\left(\mathrm{SeO}_{4}{ }^{2-}\right)$ or selenite $\left(\mathrm{SeO}_{3}{ }^{2-}\right)$, but they have the capacity to take up organic Se compounds as well. However, plants are unable to take up elemental $\mathrm{Se}$ or metal selenide compounds [5].

Alpha-tocopherol ( $\alpha$-Toc), also-called (vitamin E), is a low molecular weight lipophilic antioxidant that generally protects plants from stress-induced cellular oxidation; it is well known that exogenously applied $\alpha$ Toc is effective in improving plant growth and developmental processes under adverse environmental conditions [8]. They are naturally produced in green photosynthetic organisms $[9,10,11,12]$. The $\alpha$ tocopherol as well as $\gamma$-tocopherols are mostly present in plant membranes. Only, $\alpha$-Toc is found in photosynthetic membranes of plant leaves while $\gamma$-tocopherol is found principally in fruits, seeds and nuts [13].

Ascorbic acid (vitamin C), also known as (L-ascorbic acid), is a vitamin found in food and used as a dietary supplement [14]. Ascorbic acid is a small, watersoluble antioxidant molecule which acts as a primary substrate in the cyclic pathway for enzymatic detoxification of hydrogen peroxide. In addition, it acts directly to neutralize superoxide radicals, singlet oxygen or superoxide and as a secondary anti- oxidant during reductive recycling of the oxidized form of $\alpha$ tocopherol, another lipophilic anti- oxidant molecule [15]. 


\section{Material and methods}

The pure strain of Zea mays L. (TWC.321) seeds was kindly obtained from the Agricultural Research Center, Ministry of Agriculture, Giza, Egypt. Whereas, Sodium selenate $\left(\mathrm{Na}_{2} \mathrm{SeO}_{4}\right)$, alpha-tocopherol (vitamin $\mathrm{E}$ ) and ascorbic acid (vitamin C) obtained from Sigma Chemical Company, industrial zone, the sixth of October, Egypt. Seeds of maize under investigation were surface sterilized with $0.1 \%$ mercuric chloride for $5 \mathrm{~min}$ and washed thoroughly with several changes of sterile distilled water.

\subsection{Laboratory experiment}

was applied to study the effect of different concentrations from $\mathrm{Nacl} \mathrm{mM}$ on growth characteristics of 7-day-old maize plants. This experiment was taking place in 12 glasses petri-dishes $(8 \mathrm{~cm}$ diameter $X 10 \mathrm{~cm}$ depth) divided into 6 groups to choose salinization levels of $\mathrm{Nacl} \mathrm{(o,} \mathrm{100,} \mathrm{150,} \mathrm{200,} 250$ and $300 \mathrm{mM}$ ) respectively. All maize seeds were then soaked overnight (12 hours) in water. 5 uniform seeds placed in each clean, oven-dried petri-dish which have been lined with 2 layers of filter paper and moistened with $10 \mathrm{ml}$ distilled water or with $10 \mathrm{ml}$ of appropriate concentrations of $\mathrm{Nacl} \mathrm{mM}$ the petri-dishes were incubated under normal day/night conditions. During the experimental period, the petridishes were observed daily and distilled water or Nacl concentrations were added when needed. After 7 days plumule and radical length, fresh and dry weights of plumule and radical were estimated.

\subsection{Preliminary experiment}

was applied to study the effect of different concentrations from selenium, $\alpha$-tocopherol, and ascorbic acid each one alone on growth characteristics of 15-day old maize plants. This experiment was taking place in plastic pots containing $1 \mathrm{~kg}$ of a mixture of claysand $(2: 1 \mathrm{v} / \mathrm{v})$ soil. Respectively, seeds of maize plant under investigation were surface sterilized with $0.1 \%$ mercuric chloride for $5 \mathrm{~min}$ and washed thoroughly with several changes of sterile distilled water. They were then soaked overnight (12 hours) in either (i) distilled water to determine the concentrations of (ii) sodium selenate $\left(\mathrm{Na}_{2} \mathrm{SeO}_{4}\right)(0.25,0.5,1,5,10,15,20$ and $25 \mu \mathrm{M})$; (iii) alpha-tocopherol (50, 100, 150, 200, 250 and $300 \mathrm{ppm})$ and (iv) ascorbic acid (50, 100, 150, 200, 250 and 300 $\mathrm{ppm}$ ). After 15 day from sowing, shoot and root length, number of leaves per plant, area of leaves per plant, fresh and dry weights of shoot and roots were estimated.

\section{Statical analysis}

All experiments were conducted in a completely repeated and randomized design. The computer program SPSS (version 18) was used for statistical analyses of studied parameters. All the data are presented as mean \pm SE and subjected to analysis by one-way ANOVA followed by Duncan's multiple range test at $\mathrm{P}>0.05$. Where needed, data were transformed by $\log (\mathrm{x}+1)$ before statistical analysis.

\section{Results \\ 4.1 Laboratory experiment}

Effect of different concentrations of Nacl mM on growth criteria of 7- day-old Zea mays L. seeds. According to the results in plate (1) showed that the measured growth criteria (plumule length $(\mathrm{cm})$, radical length $(\mathrm{cm})$, fresh and dry weight (gm/plant) of plumule and radical) inhibited by increasing salinity stress on Zea mays seeds. In which maximum inhibition observed in both 250 and $300 \mathrm{mM}$ of $\mathrm{Nacl}$. On other hand, these conc $_{\mathrm{s}}$ nearly lethal to maize seed so, both of concentrations ignored in next experiments and complete next step with three conc $_{\mathrm{s}}$ only (100, 150 and $\left.200 \mathrm{mM}\right)$ Nacl.

\subsection{Preliminary experiment \\ Change in growth parameters}

The changes in growth parameters of 15- day- old maize plants in response to different concentrations of selenium as sodium selenate $\left(\mathrm{Na}_{2} \mathrm{SeO}_{4}\right)(0.25,0.5,1,5$, $10,15,20,25 \mu \mathrm{M})$ were given in figure (1a-1e) and plate (2) .The obtained result showed that the measured parameters; shoot length $(\mathrm{cm})$, root length $(\mathrm{cm})$, number of leaves/plant, area of leaves/plant and fresh and dry weight of shoot and root increasing at $0.5 \mu \mathrm{M}$ of selenium were $26.5 \%, 9.96 \%, 25 \%, 48.4 \%, 57.5 \%$, $18.2 \%, 23.6 \%$ and $28.9 \%$ respectively as compared with control maize plant. In which both concentrations 0.5 and $1 \mu \mathrm{M}$ stimulation growth parameters but, amount of increasing in $0.5 \mu \mathrm{M}$ was more than $1 \mu \mathrm{M}$ so, $0.5 \mu \mathrm{M}$ of selenium was chosen to complete in next step. In which other concentrations $(0.25,5,10,15,20$ and $25 \mu \mathrm{M})$ also ignored with $1 \mu \mathrm{M}$ in greenhouse experiment because of these treatments reduced measured parameters as compared with non-treated plant.

The changes in growth parameters of 15-day-old maize plants in response to different concentrations of $\alpha$ tocopherol $(50,100,150,200,250$ and $300 \mathrm{ppm})$ were given in figure (2a-2e) and plate (3). The obtained result showed that the measured parameters; shoot length $(\mathrm{cm})$, root length $(\mathrm{cm})$, number of leaves/plants, area of leaves/plant and fresh and dry weight of shoot and root increasing at $200 \mathrm{ppm}$ of $\alpha$-tocopherol were $6.06 \%$, $3.43 \%, 25 \%, 10.7 \%, 31 \%, 9.09 \%, 31.5 \%$ and $50 \%$ respectively as compared with control maize plant. On other hand, $50 \mathrm{ppm}$ treatment also increased measured parameters but not as the same as $200 \mathrm{ppm}$. So, $200 \mathrm{ppm}$ was chosen to complete in next step. In which other concentrations (100, 150, 250 and $300 \mathrm{ppm})$ also ignored with $50 \mathrm{ppm}$ in greenhouse experiment because of these treatments reduced measured parameters as compared with control plant.

The changes in growth parameters of 15-day-old maize plants in response to different concentrations of ascorbic acid (50, 100, 150, 200, 250 and 300 ppm) were given in figure (3a-3e) and plate [4]. The obtained result showed that the measured parameters; shoot length $(\mathrm{cm})$, root length $(\mathrm{cm})$, number of leaves/plants, area of leaves/plant and fresh and dry weight of shoot and root increasing by increasing concentrations of ascorbic acid to reach to $250 \mathrm{ppm}$ was showed maximum stimulation 
estimated by $31.6 \%, 7.01 \%, 7.5 \%, 33.6 \%, 82.8 \%$, $20.9 \%, 20.5 \%$ and $43.2 \%$ respectively as compared with non-treated maize plant. So, $250 \mathrm{ppm}$ was chosen from ascorbic acid to complete in next step.

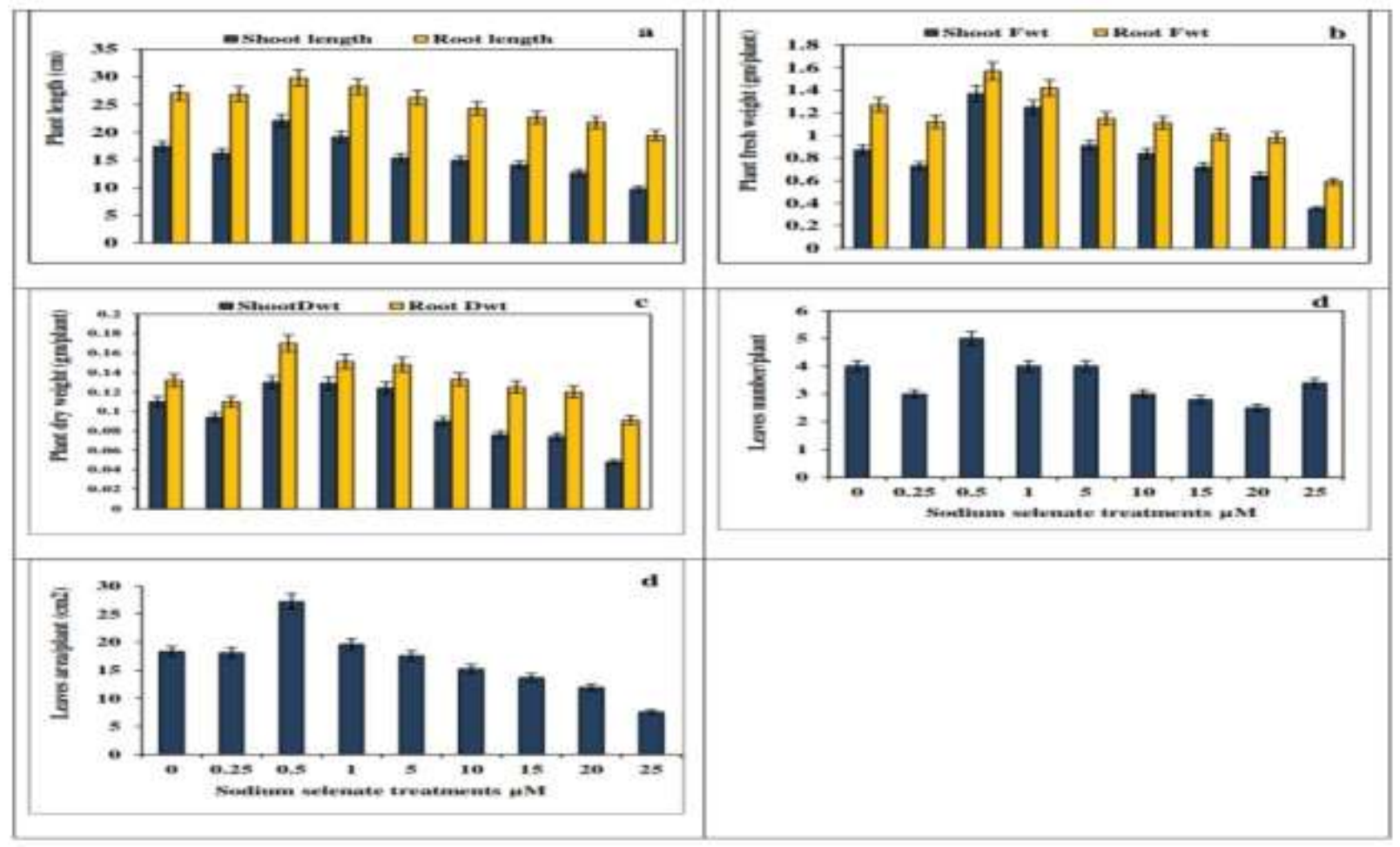

Fig (1a-1e) Effect of presoaking in different concentrations of sodium selenate on growth parameters (shoot length, root length, fresh and dry weight of shoot and root, number of leaves and leaves area per plant of 15-day-old Zea mays L. plants.

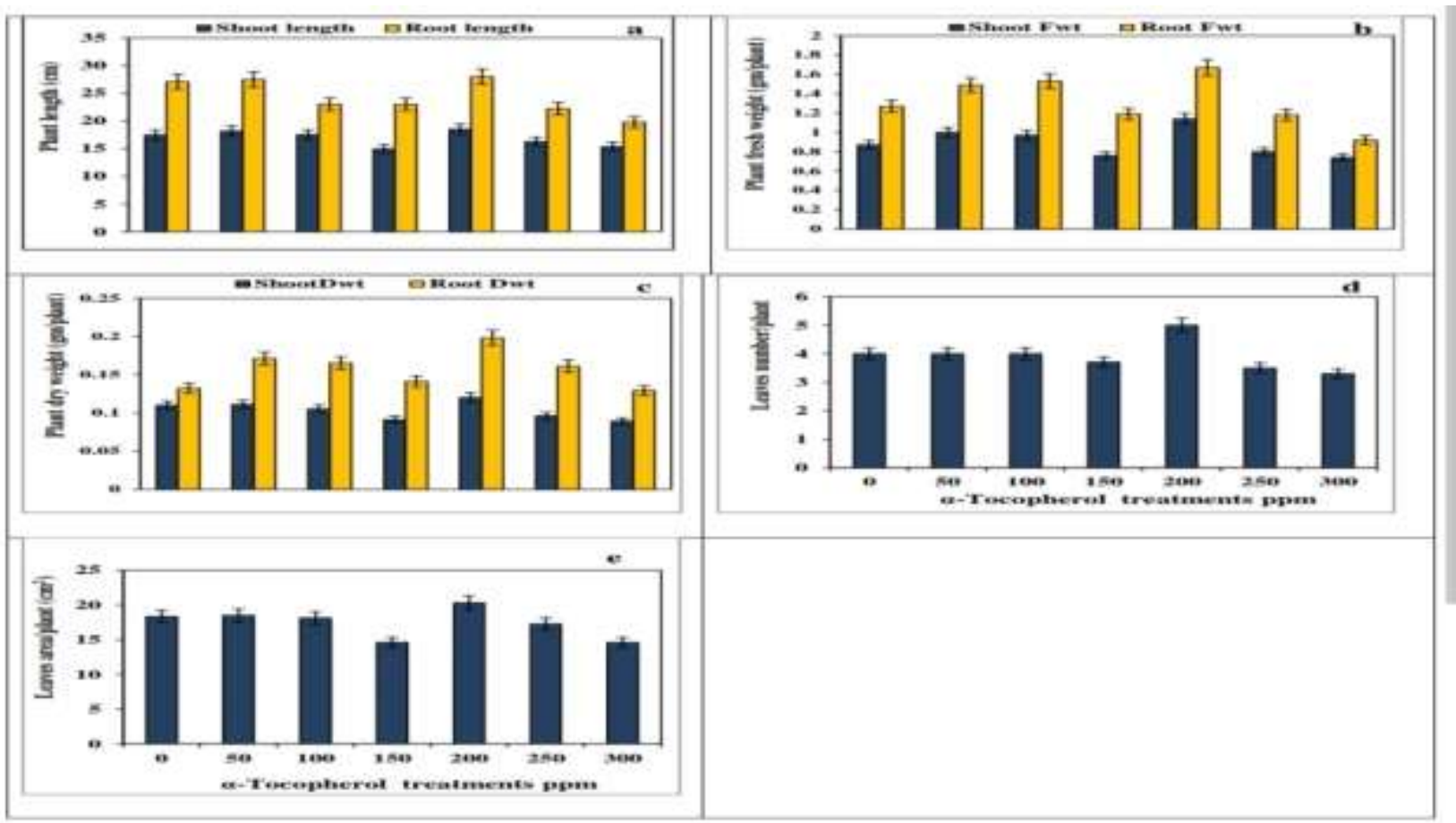

Fig (2a-2e) Effect of presoaking in different concentrations of $\alpha$-tocopherol on growth parameters (shoot length, root length, fresh and dry weight of shoot and root, number of leaves and leaves area per plant of 15-day-old Zea mays L. plants. 


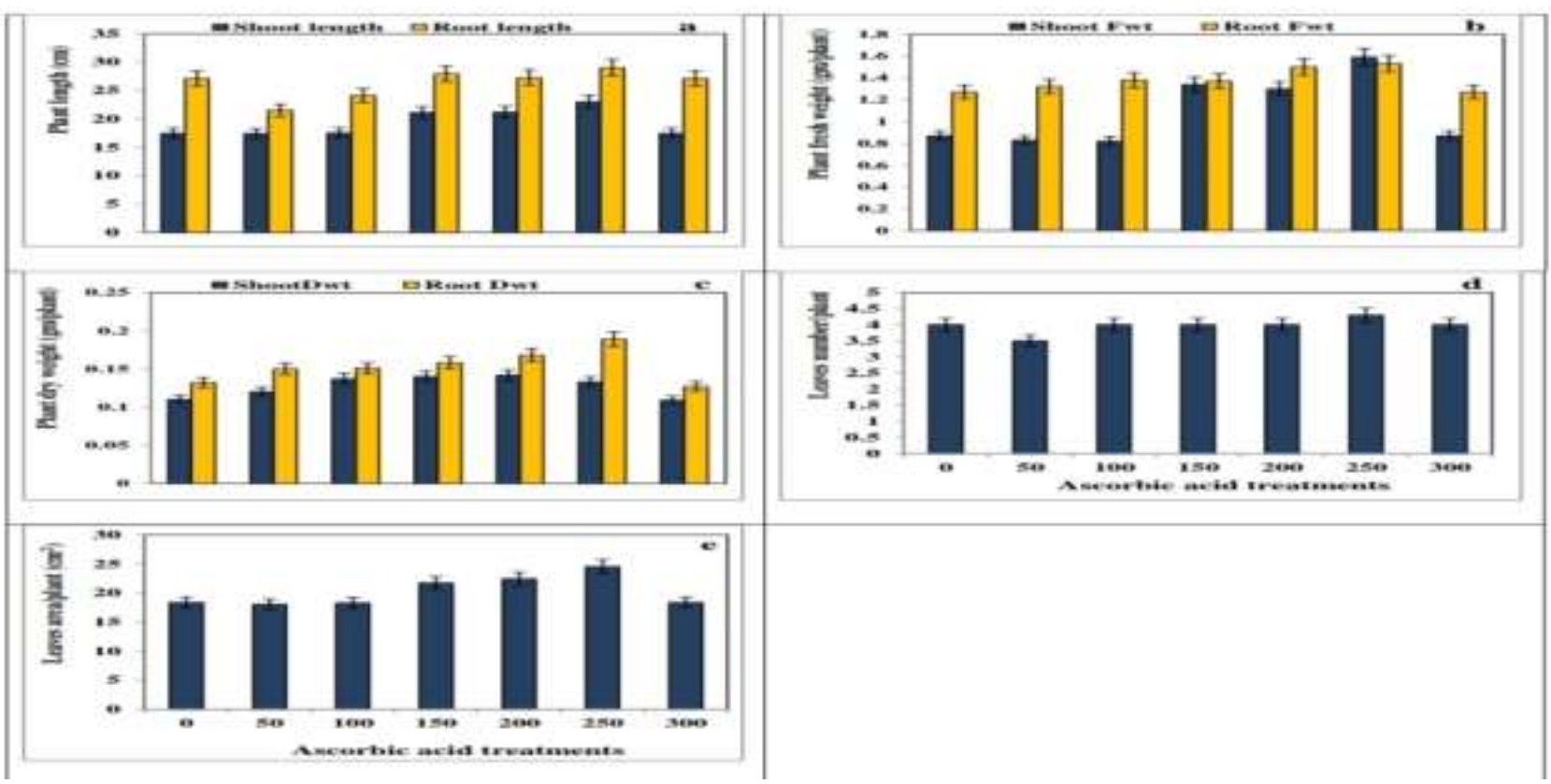

Fig (3a-3e) Effect of presoaking in different concentrations of ascorbic acid on growth parameters (shoot length, root length, fresh and dry weight of shoot and root, number of leaves and leaves area per plant of 15-day-old Zea mays L. plants.

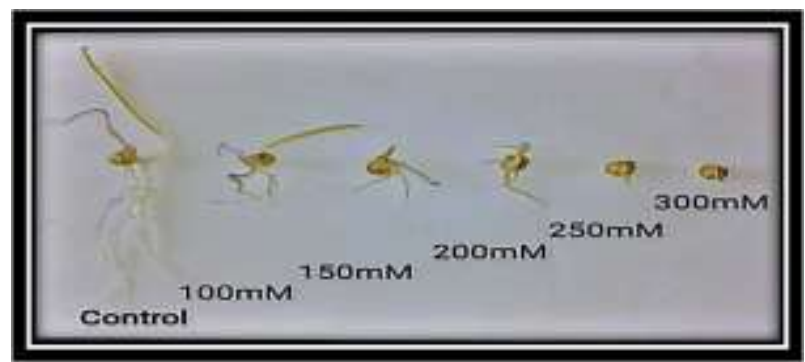

Plate (1) Effect of different concentrations of $\mathrm{NaCl} \mathrm{mM}$ on growth criteria of 7-old -day Zea mays Seeds.

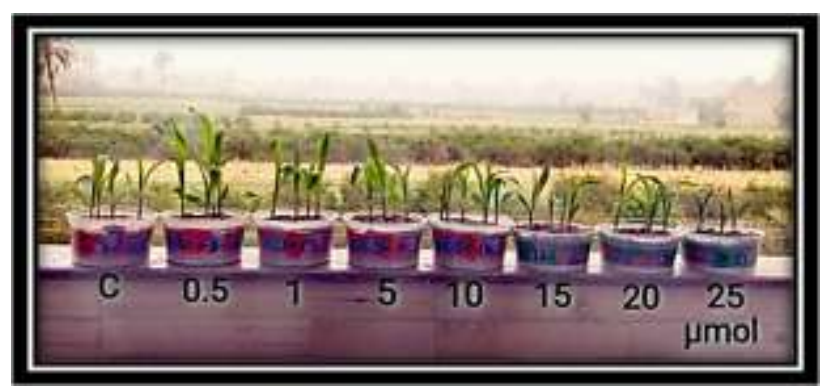

Plate (2) Effect of different concentrations of Sodium selenate $\mu \mathrm{M}$ on growth of 15-day-old Zea mays L. plants.

\section{Discussion}

Salinity is considered to be a major abiotic stress affecting germination, seedling growth, and crop production in arid and semi-arid regions [16]. Moreover, salinity has an adverse effect on seed germination of many crops, by creating an osmotic potential outside the seed, thereby inhibiting the absorption of water, or by the

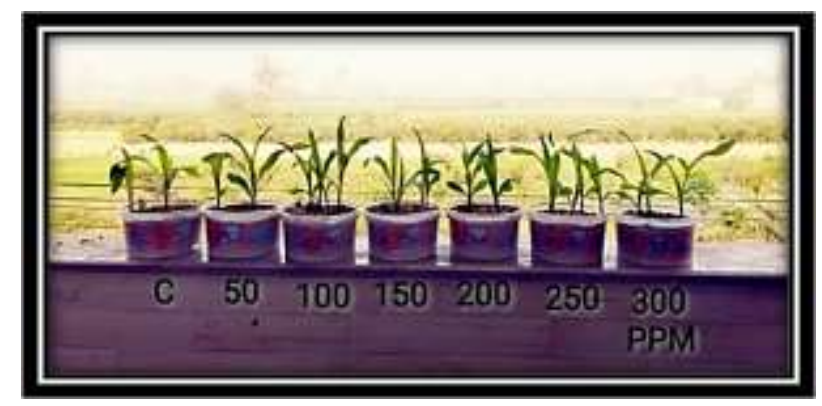

Plate (3) Effect of different concentrations of $\alpha$ tocopherol ppm on growth of 15-day-old Zea mays L. plants.

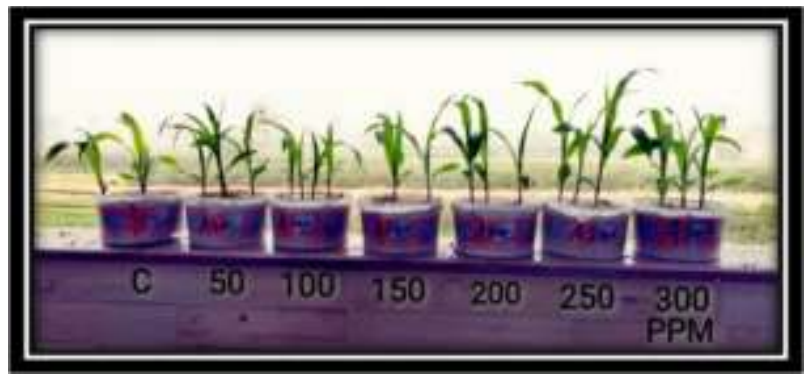

Plate (4) Effect of different concentrations of ascorbic acid ppm on growth of 15-day-old Zea mays L. plants.

toxic effect of $\mathrm{Na}^{+}$and $\mathrm{Cl}^{-}$[17]. Therefore, salinity is one of the most significant abiotic factors limiting seed germination [18]. Our result in agreement with [19] who stated that, salinity negatively influences germination of most plants.

The plant cells shrink and dehydrated immediately after salt stress is imposed, however it is recovered hours 
later. Despite this recovery, cell elongation and to a lesser extent the cell division is affected which in turn results in lower root and leaf growth rate. A week after salinity stress occurrence, lateral shoot enlargement is affected and a months later, clear differences in overall growth and injury can be noticed between salt stressed plants and their non-stressed controls. This response is due to changes in cell-water relation resultants of osmotic changes outside the root (osmotic effect), the osmotic effect leads to reduction in the capability of crops to absorb water also, similar to water stress and shows little genotypic differences [20]. These results are in agreement with those of [21], who showed that $\mathrm{NaCl}$ salinity caused a marked reduction in growth parameters (leaf area, fresh and dry weight of shoots and roots of sugar beet plants. Our results in agreement with the result obtained by [22] who showed that, plant dry weight of both maize cultivars reduced significantly under saline conditions, more reduction was observed in the salt sensitive cv.

The application of macro- and micro-nutrients is one of the management approaches for coping with environmental stresses such as soil salinity [23]. The enhanced seedling growth by seed soaking with three antioxidant compounds $\left(\mathrm{Na}_{2} \mathrm{SeO}_{4}, \alpha\right.$-toc and AsA) particularly at lower concentrations may be due to de novo synthesis of certain germination-promoting substances, promotion plant cell division, elevation effect of some hydrolytic enzymes ( $\alpha$-amylase, $\beta$ amylase and protease) that resulted in efficient utilization of seed reserves, stimulation of antioxidant activity, and increased abilities for absorbing and utilizing water, as has been concluded by [24] in soybeans [25, 26] who found that, seeds priming enhanced de novo synthesis of germination-promoting substances, membrane reorganization, activity of hydrolytic enzymes and reduced leakage of metabolites.

Selenium has been demonstrated to regulate plant growth by strengthening the stress tolerance mechanisms such as antioxidant and secondary metabolite metabolism [27], Moreover, Se could also protect the metabolism and cellular functioning by up-regulating the ROS neutralizing pathways and the osmoregulatory mechanisms [28]. A foliar application of selenate (20 $\left.\mathrm{mg} \cdot \mathrm{L}^{-1}\right)$ mitigated the adverse effects of salinity stress $\left(12 \mathrm{dS} \mathrm{m}^{-1}\right)$ on the growth and development parameters of maize (Zea mays L.) [29]. Likewise, another study reported that Se application $(20 \mu \mathrm{M})$ in the form of sodium selenate causes improvements in the growth and yield of eggplants under varying levels of soil salinity [30].

This could be attributed to the detected promotive effect of $\alpha$-Toc treatment. The $\alpha$-tocopherol levels in stressed plants are reported to be regulated in two phases [9]. In the first phase, $\alpha$-Toc synthesis occurs to scavenge the ROS, whereas in the second phase, severe stressinduced tocopherol degradation starts. The first phase is prominent in stress resistant species, whereas the second degradation phase is exclusively found in stress sensitive species [31]. A study of [32] showed that exogenously applied $200 \mathrm{mg} \mathrm{L}^{-1} \alpha$-Toc improved growth of cowpea plants. [33] applied a foliar spray of $\alpha$-Toc to cotton (Gossypium hirsutum) under water stress conditions which caused improvement in growth parameters. [34] also found an important role for $\alpha$-Toc in alleviating the deleterious effects of seawater salinity on faba beans.

Moreover, AsA application caused a significantly improvement in growth parameters which are in line with selenium and $\alpha$-tocopherol that involves in protecting proteins and lipids and induces tolerance against various abiotic stresses (e.g., drought, salt, and low temperature) $[35,36]$. The reason of AsA application improvement in maize growth might be induced stimulation in amino acids, protein, and photosynthetic pigments, which might have enhanced cell enlargement and growth of plant [37, 38]. [36, 39] have demonstrated that, canola and rice have similar improvement in plant growth in response to exogenous AsA application, respectively. [40] reported that germination of lupin seeds (Lupinus angustifolius L. var. Zapaton) increases vitamin C, vitamin E and polyphenols contents and thus, enhances antioxidant activity.

\section{Conclusion}

The present work demonstrated that, the effect of different concentrations of sodium chloride on germination of Zea mays L. seeds have a negative or lethal impact on seed germination after 7- day old maize plants. Whereas, presoaking in different concentrations especially $(0.5 \mu \mathrm{M}$ sodium selenate $), \quad(200 \mathrm{ppm} \alpha$ tocopherol) and (250 ppm ascorbic acid) for $12 \mathrm{hrs}$., each one alone enhancement growth parameters or growth rate of 15-day old maize plants.

\section{References}

[1] E. Paterniani, "Maize breeding in the tropics," CRC. Crit. Rev. Plant Sci., Vol 9 (2), pp. 125-154, 1990.

[2] N. Katerji, J. W. Van Hoorn, A. Hamdy, F. Karam, and M. Mastrorilli, "Effect of salinity on emergence and on water stress and early seedling growth of sunflower and maize," Agric. Water Manag., Vol. 26 ( 1-2), pp. 81-91, 1994.

[3] S. A. E. Ouda, S. G. Mohamed, and F. A. Khalil, "Modeling the effect of different stress conditions on maize productivity using yield-stress model," Int. J. Nat. Eng. Sci., Vol. 2 (1), pp. 57-62, 2008.

[4] M. Germ, V. Stibilj, and I. Kreft, "Metabolic importance of selenium for plants," Eur. J. Plant Sci. Biotechnol., Vol. 1(1), pp. 91-97, 2007.

[5] S. Hyun, P. E. Burns, I. Murarka, and L. S. Lee, "Selenium (IV) and (VI) sorption by soils surrounding fly ash management facilities," Vadose Zo. J., Vol. 5( 4), pp. 1110-1118, 2006.

[6] M. Rostami and H. Abbaspour, "Effect of selenium on growth and physiological traits of basil plant (Ocimum basilicum L.) under arsenic stress conditions," J. Neotrop. Agric., Vol. 6( 3), pp. 30-37, 2019.

[7] Q. Q. Chen, X. B. Yin, Z. M. Wang, L. X. Y. X. Q. Lu, F. Li, and Z. K. Liu, "Volatile organic selenium in atmosphere: A mini review," in Selenium Research 
for Environment and Human Health: Perspectives, Technologies and Advancements: Proceedings of the 6th International Conference on Selenium in the Environment and Human Health (ICSEHH 2019), October 27-30, 2019, Yangling, Xi'an, ChinaX, Vol. 60 , p. 25,2019

[8] M. Sadiq, N. A. AKRAM, and M. Ashraf, "Foliar applications of alpha-tocopherol improves the composition of fresh pods of Vigna radiata subjected to water deficiency," Turk. J. Botany, Vol. 41 ( 3), pp. 244-252, 2017.

[9] S. Munné-Bosch and L. Alegre, "The function of tocopherols and tocotrienols in plants," CRC. Crit. Rev. Plant Sci., Vol. 21(1), pp. 31-57, 2002.

[10] S. Munné-Bosch, "The role of $\alpha$-tocopherol in plant stress tolerance," J. Plant Physiol., Vol. 162 ( 7), pp. 743-748, 2005.

[11] S. Munné-Bosch, " $\alpha$-Tocopherol: a multifaceted molecule in plants," Vitam. Horm., Vol. 76 (3), pp. 375-392, 2007.

[12] J. Falk and S. Munné-Bosch, "Tocochromanol functions in plants: antioxidation and beyond," J. Exp. Bot., Vol. 61( 6), pp. 1549-1566, 2010.

[13] E. C. Grilo, P. N. Costa, C. S. S. Gurgel, A. F. de L. Beserra, F. N. de S. Almeida, and R. Dimenstein, "Alpha-tocopherol and gammatocopherol concentration in vegetable oils," Food Sci. Technol., Vol. 34( 2), pp. 379-385, 2014.

[14] N. Smirnoff, Environment and plant metabolism: flexibility and acclimation. BIOS Scientific publishers, 1995.

[15] C. H. Foyer and G. Noctor, "Tansley Review No. 112 Oxygen processing in photosynthesis: regulation and signalling," New Phytol., Vol. 146(3), pp. 359-388, 2000.

[16] G. Yohannes and B. Abraha, "The role of seed priming in improving seed germination and seedling growth of maize (Zea mays L.) under salt stress at laboratory conditions," African J. Biotechnol., Vol. 12 ( 46), pp. 6484-6490, 2013.

[17] M. Khajeh-Hosseini, A. A. Powell, and I. J. Bingham, "The interaction between salinity stress and seed vigour during germination of soyabean seeds," Seed Sci. Technol., Vol. 31( 3), pp. 715-725, 2003.

[18] R. Munns, "Physiological processes limiting plant growth in saline soils: some dogmas and hypotheses," Plant. Cell Environ., Vol. 16(1), pp. 1524, 1993.

[19] S. Mahajan and N. Tuteja, "Cold, salinity and drought stresses: an overview," Arch. Biochem. Biophys., Vol. 444( 2), pp. 139-158, 2005.

[20] R. Munns, "Genes and salt tolerance: bringing them together," New Phytol., Vol. 167( 3), pp. 645$663,2005$.

[21] C. Ghoulam, A. Foursy, and K. Fares, "Effects of salt stress on growth, inorganic ions and proline accumulation in relation to osmotic adjustment in five sugar beet cultivars," Environ. Exp. Bot., Vol. 47( 1), pp. 39-50, 2002.

[22] C. Kaya, M. Ashraf, and N. A. Akram,
"Hydrogen sulfide regulates the levels of key metabolites and antioxidant defense system to counteract oxidative stress in pepper (Capsicum annuum L.) plants exposed to high zinc regime," Environ. Sci. Pollut. Res., Vol. 25(13), pp. 1261212618, 2018.

[23] M. A. Shahverdi, H. Omidi, and S. J. Tabatabaei, "Plant growth and steviol glycosides as affected by foliar application of selenium, boron, and iron under $\mathrm{NaCl}$ stress in Stevia rebaudiana Bertoni," Ind. Crops Prod., Vol. 125, pp. 408-415, 2018.

[24] C. Lu, C. Zhang, J. Wen, G. Wu, and M. Tao, "Research of the effect of nanometer materials on germination and growth enhancement of Glycine max and its mechanism," Soybean Sci., Vol. 21( 3), pp. 168-171, 2002.

[25] Y. Fujikura and C. M. Karssen, "Molecular studies on osmoprimed seeds of cauliflower: a partial amino acid sequence of a vigour-related protein and osmopriming-enhanced expression of putative aspartic protease," Seed Sci. Res., Vol. 5(3), pp. 177181, 1995.

[26] M. Farooq, S. M. A. Basra, A. Wahid, N. Ahmad, and B. A. Saleem, "Improving the drought tolerance in rice (Oryza sativa L.) by exogenous application of salicylic acid," J. Agron. Crop Sci., vol. 195(4), pp. 237-246, 2009.

[27] C. Jiang et al., "Effect of exogenous selenium supply on photosynthesis, $\mathrm{Na}+$ accumulation and antioxidative capacity of maize (Zea mays L.) under salinity stress," Sci. Rep., Vol. 7, p. 42039, 2017.

[28] A. A. Elkelish, M. H. Soliman, H. A. Alhaithloul, and M. A. El-Esawi, "Selenium protects wheat seedlings against salt stress-mediated oxidative damage by up-regulating antioxidants and osmolytes metabolism," Plant Physiol. Biochem., Vol. 137, pp. 144-153, 2019.

[29] M. A. Ashraf, A. Akbar, A. Parveen, R. Rasheed, I. Hussain, and M. Iqbal, "Phenological application of selenium differentially improves growth, oxidative defense and ion homeostasis in maize under salinity stress," Plant Physiol. Biochem., Vol. 123, pp. 268-280, 2018.

[30] M. Butt, C. M. Ayyub, M. Amjad, and R. Ahmad, "Proline application enhances growth of chilli by improving physiological and biochemical attributes under salt stress.," Pakistan J. Agric. Sci., vol. 53( 1), 2016.

[31] K. Das and A. Roychoudhury, "Reactive oxygen species (ROS) and response of antioxidants as ROS-scavengers during environmental stress in plants," Front. Environ. Sci., Vol. 2, p. 53, 2014.

[32] M. M. Hussein, L. K. Balbaa, and M. S. Gaballah, "Developing a salt tolerant cowpea using alpha tocopherol," J. Appl. Sci. Res., Vol. 3(10), pp. 1234-1239, 2007.

[33] H.-A. Hussien, H. Salem, and B. E.-D. Mekki, "Ascorbate-glutathione-\$ $\alpha$-tocopherol triad enhances antioxidant systems in cotton plants grown under drought stress," Int. J. Chem. Tech. Res, Vol. 8, pp. 1463-1472, 2015. 
[34] S. A. Orabi and M. T. Abdelhamid, "Protective role of $\alpha$-tocopherol on two Vicia faba cultivars against seawater-induced lipid peroxidation by enhancing capacity of anti-oxidative system," J. Saudi Soc. Agric. Sci., Vol. 15(2), pp. 145-154, 2016.

[35] R. Mahalingam, N. Jambunathan, S. K. Gunjan, E. Faustin, H. U. A. Weng, and P. Ayoubi, "Analysis of oxidative signalling induced by ozone in Arabidopsis thaliana," Plant. Cell Environ., Vol. 29( 7), pp. 1357-1371, 2006.

[36] Y.-Y. Chao and C. H. Kao, "Heat shockinduced ascorbic acid accumulation in leaves increases cadmium tolerance of rice (Oryza sativa L.) seedlings," Plant Soil, Vol. 336(1-2), pp. 39-48, 2010.

[37] B. Amin, G. Mahleghah, H. M. R. Mahmood, M. Hossein, and others, "Evaluation of interaction effect of drought stress with ascorbate and salicylic acid on some of physiological and biochemical parameters in okra (Hibiscus esculentus L.)," Res. J.
Biol. Sci, Vol. 4, pp. 380-387, 2009.

[38] A. Aziz, N. A. Akram, and M. Ashraf, "Influence of natural and synthetic vitamin C (ascorbic acid) on primary and secondary metabolites and associated metabolism in quinoa (Chenopodium quinoa Willd.) plants under water deficit regimes," Plant Physiol. Biochem., Vol. 123, pp. 192-203, 2018.

[39] S. Shafiq, N. A. Akram, M. Ashraf, and A. Arshad, "Synergistic effects of drought and ascorbic acid on growth, mineral nutrients and oxidative defense system in canola (Brassica napus L.) plants," Acta Physiol. Plant., Vol. 36( 6), pp. 1539-1553, 2014.

[40] R. Fernandez-Orozco, M. K. Piskula, H. Zielinski, H. Kozlowska, J. Frias, and C. VidalValverde, "Germination as a process to improve the antioxidant capacity of Lupinus angustifolius L. var. Zapaton," Eur. Food Res. Technol., Vol. 223( 4), p. 495, 2006. 